\title{
A Cost Assessment Study for a Large-Scale Water Gas Shift Catalytic Membrane Reactor Module in the Presence of Uncertainty
}

\author{
Liang-Chih Ma, Bernardo Castro-Dominguez, Nikolaos K. Kazantzis*, Yi Hua Ma \\ Center of Inorganic Membrane Studies, Department of Chemical Engineering, \\ Worcester Polytechnic Institute (WPI), Worcester, Massachusetts 01609-2280, USA
}

\begin{abstract}
A comprehensive economic performance evaluation framework for an actual large-scale watergas-shift Pd-based catalytic membrane reactor (CMR) module for hydrogen production is presented. Since a detailed assessment of the technical performance of the CMR built at WPI has been reported previously [1], the present research study focuses on an assessment of the module's economic performance characteristics, and thus, can be viewed as complementary. The proposed evaluation framework encompasses comprehensive baseline models for both Fixed Capital Investment (FCI) and Total Capital Investment (TCI) while various sources of uncertainty are identified whose effect on CMR's economic performance is explicitly taken into account using Monte Carlo techniques. As a result, insightful distribution profiles of FCI and TCI are derived rather than single-point value estimates and more realistic distributions of CMR economic performance outcomes are generated and statistically characterized. The latter could potentially inform development efforts of this new technology option for hydrogen production purposes.
\end{abstract}

* Author to whom correspondence should be sent; Address: 100 Institute Road, Department of Chemical Engineering, Worcester Polytechnic Institute, Worcester, MA 01609-2280, USA; E-mail address: nikolas@wpi.edu, Phone number: +1-508-8315666. Part of this work was performed while N. Kazantzis was at Hughes Hall, University of Cambridge, UK. 


\section{Introduction}

Palladium membranes separate $\mathrm{H}_{2}$ from gas mixtures such as syngas $\left(\mathrm{CO}_{2}, \mathrm{CO}, \mathrm{H}_{2} \mathrm{O}\right.$, $\mathbf{N}_{2}$ ), commonly derived from coal gasification units in power generation with high efficiency through the solution-diffusion mechanism. First, molecular hydrogen undergoes a dissociative adsorption process, leading to the dissolution and diffusion of atomic hydrogen through the metallic layer which is driven by a transmembrane hydrogen partial pressure difference. Tehn, atomic hydrogen associates on the permeate side surface allowing molecular $\mathrm{H}_{2}$ to desorb from the surface [2]. Consequently, a theoretically infinite selectivity can be achieved at high fluxes as well as good chemical and physical stability [3]. Furthermore, it has been shown that alloying Pd with other metals such as $\mathrm{Cu}, \mathrm{Au}, \mathrm{Pt}$ and $\mathrm{Ag}$ enhances the $\mathrm{H}_{2}$ permeance of the membrane and its resistance to $\mathrm{H}_{2}$ embrittlement [4].

Palladium-based catalytic membrane reactors (CMRs) represent an efficient technology option that increases the conversion of chemical reactions and accordingly improves product recovery levels $[5,6]$. Subsequently, the production of hydrogen in CMRs via natural gas steam reforming (MSR) and water-gas shift (WGS) of the coal-derived syngas generates strong interest as an alternative clean process system. In particular, the application of membrane technology to the water-gas shift (WGS) reaction has been shown to be efficient technically and economically [7]. In a WGS CMR module, the catalyst is confined within the reactor (retentate) along with a tubular palladium membrane situated throughout the reaction zone (Figure 1). The membrane continuously removes "in-situ" the $\mathrm{H}_{2}$ generated which, in accordance to Le-Chatelier's principle, allows higher CO conversions to be attained and potentially supported by process intensification strategies [1,8]. Notice that this approach yields conversions that exceed the ones commonly attained in conventional packed bed reactors. Additionally, the higher retentate pressure facilitates the acquisition of clean pressurized $\mathrm{CO}_{2}$ and water, thus enabling the process of carbon capture. For all the aforementioned technical features, Pd-based CMRs have shown to represent an important technology option for the development of $\mathrm{H}_{2}$ economy [8].

In CMRs, the reaction and separation processes are conducted simultaneously, and therefore, the high- and low-temperature shift reactors along with a hydrogen separation unit, 
such as pressure swing adsorption (PSA) in the traditional hydrogen production system $[9,10]$ can be eliminated from the structure of the overall process system. Additionally, the simultaneous separation of $\mathrm{H}_{2}$ and $\mathrm{CO}_{2}$ is particularly appealing due to increasing efforts focusing on the reduction of carbon dioxide emissions [11,12]. When compared to the conventional hydrogen production process, a CMR allows lower temperatures of operation, while still reaching higher conversion levels; this enables prolonged catalyst lifetime, lower production costs, reduced material costs for the reactor and a facilitated route for carbon capture. Moreover, process intensification in CMR technology provides compactness, modularity, reduced equipment size to production capacity ratio, practical assembly/disassembly capabilities and operational flexibility [13].Additional advantageous features include the good allocation of material and energy resources, waste management and superior environmental performance [14].

Many studies have been reported regarding the potential industrial applications of Pdbased CMR technology, but their results rely on a proof-of-concept-centered approach $[15,16]$, giving rise to significant challenges for techno-economic performance evaluation in the absence of any accumulated operating experience at the commercial scale and reliable data. Furthermore, the few large-scale tests of CMRs under actual industrial conditions that have been published do not offer comprehensive sets of pertinent techno-economic data. The study by Catalano et al [1] showed that $\mathrm{H}_{2}$ production of $1.2 \mathrm{lb}$ /day with purity higher than $99 \%$ can be reached through a WGS-CMR using a gas mixture similar to an actual syngas composition. The surface area of the membrane used in this work was $200 \mathrm{~cm}^{2}$ with operating conditions corresponding to a temperature range of $420-440^{\circ} \mathrm{C}$ and a retentate pressure of 20 bar. In Figure 1, a photograph of the CMR rig shows its different components, including the mass flow and pressure controllers, the preheater, the heat exchangers, and back pressure regulators. Furthermore, Patrascu et al. [17] reported the use of a large scale CMR for methane steam reforming (MSR) capable of achieving a $\mathrm{H}_{2}$ permeate flow rate of $1.6 \mathrm{NL} / \mathrm{min}$ while utilizing a membrane with a surface area of 175 $\mathrm{cm}^{2}$ and being operated at temperatures within the $440-525^{\circ} \mathrm{C}$ range and at a pressure of $10 \mathrm{bar}$. Moreover, Ma et al. [18,19] demonstrated the satisfactory performance characteristics of different $\mathrm{Pd}$ and $\mathrm{Pd} /$ alloy membranes under actual coal-derived syngas and industrial scenarios but solely for $\mathrm{H}_{2}$ purification purposes. 
Over the years, our group $[14,20,21,22,23,24]$ has developed a comprehensive economic performance assessment framework to evaluate Pd-based CMR technology integrated into power and hydrogen production plants with the purpose of identifying market and regulatory conditions that allow this new technology option to generate superior economic performance outcomes when compared to the traditional ones. In particular, Monte Carlo simulation methods were integrated into the above framework in order to explicitly take into account various sources of irreducible uncertainty in the fuel market and regulatory environments. Such a methodological context enables a comprehensive evaluation of economic performance characteristics of CMRs while overcoming the limitations of conventional valuation/assessment methods that rely on single-point value estimates. The present research study focuses on building upon the promising results reported in $[14,20,21]$ in order to evaluate the profile of economic performance outcomes generated by the large-scale WGS CMR module reported by Catalano et al. [1] under the aforementioned uncertainties. The objective of the present study is to obtain realistic profiles of economic outcomes and other valuable information by explicitly acknowledging uncertainty sources, and therefore, inform potential demonstration and deployment efforts of CMR technology in an industrial setting. In particular, the contribution of this study can be traced in the following directions:

i) In the presence of new knowledge and available data, the present research work offers a systematic and comprehensive framework to reliably assess and characterize the cost profile of a new technology option realized by an actual large-scale membrane reactor module

ii) In the absence of any significant accumulated operating experience regarding this new membrane reactor module, the present research work provides preliminary insights regarding its economic viability in the presence of uncertainty that could inform potential efforts to incentivize the technology demonstration stage

iii) Within the above context, the proposed framework seamlessly incorporates "learning effects" (through the associated learning curves) on cost profiles as pertinent technology advances and also demonstrates the effect of economies of scale. 
For further details regarding the configuration/structure of the large-scale CMR system considered in this study as well as its technical performance characteristics the interested reader is referred to the above bibliographical references.

The present study is organized as follows: the main structural components of the proposed economic performance evaluation framework are presented in Section 2, followed by a presentation of the study's main results and a thorough discussion on its most important findings in Section 3. Finally, some concluding remarks and recommendations are offered in Section 4.

Figure 1. Schematic of a CMR module for water gas shift reaction and picture of the actual CMR rig built at WPI

\section{Economic Performance Assessment Framework under Uncertainty}

In traditional economic performance assessment frameworks that rely on single-point value estimates and inherently uncertain model inputs are considered "fixed" at average values (representing "best guesses"), the so called "flaw of averages" could emerge leading to unsatisfactory and potentially misleading assessment conclusions. Indeed, economic assessments based on average/expected conditions do not necessarily represent the average/expected economic performance outcome due to Jensen's inequality in probability theory [25,26]. A rigorous and methodological sound way to overcome the aforementioned potential "flaw" in conventional cost assessment studies under uncertainty is to employ Monte Carlo techniques through which the expected value generated for the primary economic performance metrics used in the present study (namely FCI and TCI) represents an unbiased estimator of the sample's average [25,26]. Subsequently, the key objective of the present study is to develop a systematic, scientifically sound and reliable economic performance assessment and cost analysis framework for an actual large-scale CMR module for WGS while taking explicitly into consideration various sources of irreducible uncertainty. To attain this goal, Monte Carlo simulation methods are integrated into detailed models of Fixed Capital Investment (FCI) and Total Capital 
Investment (TCI) with the purpose of deriving probability distribution profiles in the presence of uncertainty associated with the market, regulatory and process operating environment. It is important to mention that this work uses the FCI/TCI as the primary economic indicator, rather than the Net Present Value (NPV) and/or Total Product Cost (TPC) [20-24]. Indeed, in cost assessment studies as in the present one, the focus is placed on deriving the range of outcomes associated with FCI/TCI (the probabilistic profile being amenable to insightful statistical characterization) rather than the future stream of revenues that is generated through product sales and thus subjected to uncertain demand and price patterns (as in the NPV-calculation). Furthermore, we believe that the proposed FCI/TCI-based cost assessment study is a meaningful one deriving its legitimacy from the fact that it focuses on the economic performance of a single piece of equipment or technology unit (the WGSCMR module) rather than the performance of a plant where the above technology option is integrated for the production of a valuable commodity.

Within the proposed economic performance evaluation framework comprehensive baseline models for the FCI and TCI are developed first, while Monte Carlo simulation methods are then integrated into the FCI and TCI baseline models to explicitly take into account the various uncertain model inputs [21]. As shown in Eq. 1 and Eq. 2 below, in the baseline functional FCI/TCI model formulation, the FCI is calculated as the sum of all direct costs (DC) and indirect costs (IC) while the TCI is estimated by forming the sum of the FCI and the working capital (WC) in compliance with standard practices in economic analysis of engineering systems [26]. Table 1 and Table 2 show the 21 cost model inputs considered in the FCI/TCI estimation. Please notice that the cost figures of purchased equipment involving the Pd-based CMR and assorted apparatus, such as the micro gas chromatography (GC) system, the high pressure liquid metering pump, and the pressure monitor system, are adopted from the actual large-scale CMR module built in the facilities of Worcester Polytechnic Institute (WPI) and shown in Figure 1 with their specifications listed in Table 3 [1]. Furthermore, the range of percentages indicated in Table 1 and Table 2 are approximations, reflecting the effect of many factors in uncertain "future states" on the FCI/TCI, including the module location, type of process, and complexity of the equipment. Furthermore, the cost figures obtained from the actual large-scale CMR module are updated by means of the Chemical Engineering Plant Cost Indexes (the most recent ones available for the year 2014) in order to obtain the most recent equivalent 
cost figures [27]. For the reader's convenience, the main equations used are shown in Table 2 and explicitly described by Eq. 1 and Eq. 2 below:

$$
\begin{gathered}
\mathbf{F C I}=\mathbf{D C}+\mathbf{I C} \\
\mathbf{T C I}=\mathbf{F C I}+\mathbf{W C}
\end{gathered}
$$

Table 1: Estimation of production costs for Pd composite membrane ${ }^{\dagger}$

Table 2: Estimation of Capital Investment for a large-scale Pd-based CMR module*

Table 3: Pd-based CMR specifications used for cost analysis

The integration of Monte Carlo simulation methods into the proposed economic assessment framework requires that uncertain model input variables are identified first following probabilistic representations that conform to ranges of reasonable empirical estimates for chemical plants derived from plant operations as well as expert opinion (reported in a comprehensive manner in the standard monograph by Peters et al. [26]) (please refer to Table 4). For the uncertain model input variables, three types of probability distributions have been used: bootstrap distributions and simple uniform and triangular distributions. The bootstrap distribution is developed using standard re-sampling techniques known as bootstrapping statistics. This method, in particular, is being used in the presence of available historical or experimental data [25,28,29]. Additionally, the simple uniform and triangular distribution methods are used in the absence of any reliable pertinent data at the commercial scale [14,30,31] using meaningful minimum, center and maximum values of the associated random variables derived from the above sources..

Table 4: Probability distributions associated with various uncertainty drivers

After identifying all uncertainty variables, random sampling from the aforementioned distributions via a Monte Carlo simulator is conducted, allowing these model input uncertainties to propagate through the FCI/TCI models, and consequently generate probabilistic distribution profiles of the FCI/TCI for cost analysis purposes. The Monte Carlo simulation is performed 
using the software package XLSim with $10^{4}$ iterations for each run as shown in the simulation procedure schematic in Figure 2. Please notice that the aforementioned "flaw of averages" can be effectively overcome by taking into account the impact of uncertainties on the economic estimation through Monte Carlo simulation methods, thus allowing the probabilistically correct ("unbiased") estimation of the corresponding expected/average value [25].

Figure 2: Procedural steps of the Monte Carlo simulation method [14]

\section{Main Results and Discussion}

An economic performance assessment of an actual large-scale Pd-based CMR module has been conducted with the integration of standard Monte Carlo simulation methods that take into account inherent sources of uncertainty. Figure 3 shows cumulative probability distribution profiles as well as associated expected values for the FCI and TCI demonstrating the economic performance of this new technology option in a statistical and more realistic manner compared to traditional single-point-based cost studies. In particular, it is easy to observe that there is a $20 \%$ chance for the TCI to be lower than $\$ 400 \mathrm{k}$, while there is a $10 \%$ probability for the FCI to be higher than $\$ 450 \mathrm{k}$. In addition, it is useful to quantify the "value at opportunity" and the "value at risk" at a predetermined probability level for further study and discussion. In the present study, the "value at opportunity" is defined as $\mathrm{P}_{5}$, representing the $5 \%$ probability for a capital investment cost to be lower than the $\mathrm{P}_{5}$ threshold-value; while the "value at risk" is characterized as $\mathbf{P}_{95}$, showing the $\mathbf{5 \%}$ probability for a capital investment cost to be higher than the $\mathbf{P}_{\mathbf{9 5}}$ threshold-value or the $95 \%$ probability to be lower than the $\mathbf{P}_{95}$ threshold-value. Furthermore, the expected values of the TCI and FCI (ETCI/EFCI) have an outcome frequency of $52 \%$ as shown in Figure 3. The features of the cumulative distribution profiles for EFCI, ETCI, $\mathrm{P}_{95}$ and $\mathrm{P}_{5}$ for the CMR module are summarized in Table 5.

Figure 3: Cost distribution profiles of the WGS-CMR module

Table 5: WGS-CMR module cost summary 
The module cost per membrane unit area for the actual large-scale system, $\mathrm{P}_{95}, \mathrm{P}_{5}$, and the expected values for the FCI/TCI shown in the present study surpass the industrial-scale CMR module cost previously reported [14]. The ETCI for an industrial-scale CMR [14] is $\$ 18,805 / \mathrm{m}^{2}$ which is approximately 1,200 times lower than the ETCI delineated in this work or $\$ \mathbf{2 2 , 4 1 8}$ $\mathbf{k} / \mathbf{m}^{2}$. Based on the six-tenths factor rule [32], the cost reduction in large-scale units can be attributed to a scale-up effect, which induces reasonable cost-reducing prospects on equipment costs at higher capacities. Furthermore, the design of a multiple tube membrane module and the elimination of the potentially overlapping auxiliary process components and assorted apparatus contribute further to the discrepancies in economic outcomes between the industrial- and largescale CMR modules. It should be pointed out that the key cost components of the FCI/TCI models are strongly dominated by the purchased equipment cost and consequently, the lower module cost per membrane area presented in an industrial-scale seems reasonable.

The costs associated with economies of scale were further studied by investigating the effect of capacity on the normalized TCI of WGS-CMR modules, as shown in Figure 4. The upscaling factor, previously computed as the six-tenths factor rule, was included in the stochastic model as one of the uncertain drivers with a reasonable range of 0.4 to 0.8 and a most likely value of 0.6 [26]. Changes in the upscaling factor resulted in a significant decrease in the normalized TCI of CMR modules (Figure 4). For example, when the capacity is increased from $1.2 \mathrm{lb} /$ day to $1000 \mathrm{lb} /$ day, the normalized TCI is reduced by $92 \%$ from $378,458 \$ /(1 \mathrm{~b} /$ day) to $29,916 \$ /(\mathrm{lb} /$ day $)$. Additionally, Figure 4 clearly shows that when the capacity is increased to the aforementioned industrial-scale CMR [14], the TCI of the module lays accordingly (shown as an individual red point). These results clearly validate the ones of previously published work in CMRs [14,20,21,22], since actual techno-economic features were used in this study. It is suspected that the slight discrepancy between the expected value of this work and that reported previously [14] at the industrial scale is caused by the reduction of raw material costs and/or certain features associated with inventories of scale. Notice that the spread of the $\mathrm{P}_{95}$ and $\mathrm{P}_{5}$ values $\left(\mathrm{P}_{95}-\mathrm{P}_{5}\right)$ becomes more obvious as the capacity increases, implying that the risk increases accordingly, possibly due to unknown factors of upscaling such as safety, land, regulatory parameters and others. The apparent deviation between the industrial-scale and our actual 
large-scale module cannot be solely attributed to the combined effect of all uncertainties considered. Nonetheless, the fact that the ETCI of the industrial WGS-CMR module lays within the extrapolated ranges associated with the derived TCI distribution profiles of the actual large-scale CMR, demonstrates the accuracy levels of the proposed cost assessment model. In other words, the cost estimates relevant to the industrial-scale WGS-CMR module falls within the spread of the aforementioned extrapolated TCI estimates, and therefore, although different approaches were used in the present assessment study and the industrial one, their predictions are quite similar.

In addition, the results presented in Figure 4 imply that scaling up the module can effectively reduce the levelized cost of hydrogen, which was estimated as the total product cost (TPC) divided by the hydrogen production. Notice that the TPC greatly depends on the TCI as standard practice in the economic analysis of engineering systems suggests $[21,26]$. For instance, the financing interest in the TPC is about $6-10 \%$ of the TCI.

Figure 4: Normalized Total Capital Investment of WGS-CMR modules for various capacities.

The effects of uncertainty on the ETCI value for the large-scale CMR module are analyzed through the Tornado diagram presented in Figure 5. Please notice that a Tornado diagram graphically illustrates the relative impact on the TCI profile of variations of the different uncertain model inputs considered in the present study. Specifically, the change of the ETCI caused by the variation of each input over its prescribed range from the lowest to the highest value is depicted with a bar in the Tornado diagram, under the assumption that all other model inputs remain at their baseline values. Afterwards, all bars are sorted from long to short, in order to reliably assess the relative impact of various uncertain model inputs on TCI-relevant performance characteristics [33]. Therefore, the major advantage of using a Tornado diagram in this study is to illustrate which uncertain model inputs have the greatest impact on the expected value of TCI.

Figure 5: Tornado diagram for Total Capital Investment 
The ETCI-Tornado diagram of the large-scale CMR module is based on the following values: Pd unit price: 17.7-28.2 \$/g; electroless plating setup cost: $\$ 1,000-2,000$; operating labor to raw materials ratio range: $12.5-50 \%$; direct supervisory and clerical labor to operating labor ratio range: $10-20 \%$; utilities to raw materials ratio range: $12.5-50 \%$; maintenance and repair to electroless plating setup cost ratio range: 2-10\%; operating supplies to electroless plating setup cost ratio range: $0.5-1 \%$; laboratory charges to operating labor ratio range: $10-20 \%$; patents and royalties to raw materials ratio range: $0-15 \%$; installation to purchased equipment ratio range: 25-55\%; instrumentation and controls, installed to purchased equipment ratio range: 8-50\%; piping, installed to purchased equipment ratio range: $10-80 \%$; electrical, installed to purchased equipment ratio range: 10-40\%; buildings, process and auxiliary to purchased equipment ratio range: $10-70 \%$; service facilities and yard improvements to purchased equipment ratio range: 40$100 \%$; land to purchased equipment ratio range: $4-8 \%$; engineering and supervision to direct cost ratio range: 5-30\%; legal expenses to fixed capital investment ratio range: $1-3 \%$; construction expense and contractor's fee to fixed capital investment ratio range: 10-20\%; contingency to fixed capital investment ratio range: 5-15\%; working capital to total capital investment ratio range: $10-20 \%$; capacity of purchased equipment: $\pm 20 \%$.

As shown in Figure 5, the capacity of purchased equipment has the most significant impact on the TCI performance, suggesting that the purchased equipment cost greatly determines the value of TCI. Please also notice that the TCI increases by $11 \%$ when the capacity of purchased equipment is increased by $20 \%$, while the TCI decreases by $13 \%$ when the capacity of purchased equipment is reduced by $20 \%$, (which is indicative of the significant impact of the CMR module capacity on TCI performance). As a result, since the purchased equipment costs for a larger capacity, such as in an industrial-scale CMR module case, would be significantly reduced from those presented in the large-scale CMR module, a significant reduction in cost for an industrial-scale CMR seems indeed a valid conjecture. Additionally, membrane features such as Pd unit price and operating labor show a marginal effect on TCI performance when compared to the capacity of purchased equipment. Indeed, the potential economy of scale has shown to significantly influence the economic profile characteristics of CMR technology; however these 
features can also be the result from the specific postulated learning curves, spreading of set-up costs and certain stochastic processes associated with inventories [34].

Scaling up the capacity of CMRs appears to be the next step towards the deployment of this innovative technology. Nonetheless, it is important to consider that the increase in size of a plant/technology is not totally influenced by capital costs, market growth or the magnitude of investments, but rather by a steady technological progress over time as shown by Lieberman [35]. Technological progress over time is captured by learning or experience curves which describe the reduction of capital costs due to upscaling, mass production, process improvements, learning-by-doing, and reduction in raw material costs [36]. In this work, TCI learning curves of the CMR technology were generated taking into consideration the inherent uncertainties reflected in Eq. 3 [37,38].

$$
\mathrm{TCI}(\mathrm{q})=\mathrm{TCI}_{0} \times \mathrm{q}^{\alpha}
$$

Where TCI (q) is the total capital investment [k\$] after learning a cumulative production of WGS-CMR modules (q), $\mathrm{TCI}_{0}$ is the initial total capital investment of the WGS-CMR module $[\mathrm{k} \$$ and $\alpha$ is the learning index. Notice that the learning index was estimated based on statistical progress ratios reported by Christiansson [37], and assuming that the WGS-CMR module belongs to the category of "Modules". The progress ratio was treated as one of uncertain drivers of the TCI estimation modeling framework with a maximum, average and minimum value of 0.7 , 0.83 , and 0.95 , respectively. It is important to mention that the progress ratios considered in this work were assumed to be stable over time and that the phase of plant (start-up or production) did not influence the rate of learning.

The TCI learning curves, represented in Figure 6, depict significant reductions as the cumulative production of the modules increase, indicating that process improvement and learning-by-doing significantly affect the economic features of a developing technology option such as WGS-CMR modules. For example, when the cumulative production of modules increases to 100 ; there is a $70 \%$ reduction in the TCI from $\$ 454,149$ to $\$ 137,692$. The factors lying behind a learning curve are associated with process improvement and learning-by-doing, such as labor efficiency, system redesign, improved manufacturing methods, new cost-effective materials, and improved construction efficiency [36]. Furthermore, although, experience in 
manufacturing reduces the risk in any given technology option; Figure 6 shows an increase in the spread of $\mathrm{P}_{95}$ and $\mathrm{P}_{5}$ as the cumulative number of produced CMR module increases. The increase in risk $\left(\mathrm{P}_{95}-\mathrm{P}_{5}\right)$ as more units are produced is caused by assuming constant progress ratios over time; in other words, it is assumed that the start-up and the production stage have the same learning curves.

The combination of manufacturing experience and the upscaling process will lead to significant cost reductions. Therefore, it is recommended that future research efforts focus on generating further operating experience and plant data at a pilot/commercial scale as well as studies on CMR manufacturing characteristics and challenges.

Figure 6: Experience curve for Total Capital Investment of WGS-CMR modules.

\section{Concluding Remarks and Recommendations}

A comprehensive economic evaluation framework for an actual large-scale catalytic membrane reactor module used for water-gas-shift (WGS) reaction has been developed through detailed baseline models for the Fixed Capital Investment (FCI) and the Total Capital Investment (TCI) under various sources of uncertainty. The effect of these uncertainty sources has been taken into account through the integration of Monte Carlo simulation methods. Accordingly, distribution profiles of these economic indicators have been derived rather than single-point value estimates, and a more realistic distribution of CMR economic performance outcomes has been generated through which "risks" and "opportunities" were identified. The results shown for the actual large-scale CMR displays much higher expected values for the FCI/TCI than that of an industrial-scale, indicating that TPC profiles become economically appealing when the capacity of the CMR module increases. Additionally, it is shown that the capacity of purchased equipment is a critical factor in TCI performance assessment studies. This work effectively validated previous techno-economic results on CMR technology, utilizing actual data and reasonably extrapolating through the economics of scale. A Tornado diagram has been developed to identify the relative impact of the various uncertainty drivers on TCI, as well as elucidate the sensitivity 
of the ETCI with respect to equipment capacity. A TCI learning curve for the CMR modules has also been generated to demonstrate the importance of technological progress over time on the economic features of this innovative technology option.

Finally, within the context of this work, a few recommendations could potentially inform efforts to provide creatively structured incentives aiming at accelerating the realization of demonstration projects for this novel technology as well as improve the necessary techno-economic evaluation:

1) Engineers, managers, technology policy experts need to be aware of the fact that irreducible sources of uncertainty with asymmetric impact on the system's economic performance outcomes/profile (which is an inherent characteristic/feature of complex systems) should always be explicitly acknowledged and integrated into a comprehensive cost assessment framework through integrated Monte Carlo techniques

2) Learning effects and economies of scale need also be considered within the economic performance assessment framework to potentially unlock investment in novel technology options.

3) Larger units at the commercial scale need to be built and tested in order to generate more reliable data as well as accumulate useful operating experience that could eventually reduce technology risks and enhance economic performance evaluation.

\section{Acknowledgements}

The authors are grateful to the anonymous reviewers as well as Professor Van der Bruggen

for their time, efforts, insightful remarks and helpful suggestions that resulted in an improvement of the paper's content. Financial support provided by the U.S. Department of Energy through grant No. DE-FE0004895 is also gratefully acknowledged by the authors. 
Table 1 Estimation of production costs for Pd composite membrane ${ }^{\dagger}$

\section{Electroless plating setup cost}

\section{Production costs}

1. Raw materials

(a) $\mathrm{Pd}$ cost

(b) 316L SS support

2. Operating labor (12.5-50\% of raw materials)

3. Direct supervisory and clerical labor (10-20\% of operating labor)

4. Utilities (12.5-50\% of raw materials)

5. Maintenance and repair (2-10\% of electroless plating setup cost)

6. Operating supplies (0.5-1\% of electroless plating setup cost)

7. Laboratory charges (10-20\% of operating labor)

8. Patents and royalties ( $0-15 \%$ of raw materials)

${ }^{\dagger}$ Please notice that the $316 \mathrm{~L}$ SS support cost is updated to 2014 by Chemical Engineering Plant Cost Indexes. 
Table 2 Estimation of Capital Investment for a large-scale Pd-based CMR module

\author{
I. Direct Costs \\ A. Equipment + installation + instrumentation + piping + electrical + insulation + \\ painting
}

1. Purchased equipment

a. Micro GC system

(1) Micro GC $\times 1$

(2) $\operatorname{Trap}\left(\mathrm{H}_{2} \mathrm{O}\right) \times 2$

(3) Big universal trap $(\mathrm{He}) \times 2$

b. High pressure liquid metering pump

c. Pressure monitor system

(1) Manometer (range: 25000 Torr) $\times 2$

(2) Manometer (range: 5000 Torr) $\times 1$

(3) Digital power supply and readout $\times 2$

d. Drain valve

e. Mass flow control system

(1) Mass flow controller $\times 4$

(2) Mass flow indicator $\times 2$

(3) Pressure controller $\times 2$

(4) Flow-Bus interface box $\times 1$

(5) Digital readout/control unit blind front $\times 2$

f. Chiller

g. Temperature control system

(1) Temperature controller $\times 2$

(2) Profile Probe $\times 2$

(3) Thermocouple differential analog input module $\times 3$

(4) CompactDAQ chassis $\times 1$

h. Computer

i. Preheater

(1) Shell casing

(2) Ceramic fiber heater

j. Pd-based catalytic membrane reactor

(1) Pd composite membrane

(2) High temperature shift catalyst

(3) Shell casing

(4) Ceramic fiber heater

2. Installation (25-55\% of purchased equipment)

3. Instrumentation and controls, installed (8-50\% of purchased equipment)

4. Piping, installed (10-80\% of purchased equipment)

5. Electrical, installed (10-40\% of purchased equipment) 
B. Buildings, process and auxiliary (10-70\% of purchased equipment)

C. Service facilities and yard improvements (40-100\% of purchased equipment)

D. Land (4-8\% of purchased equipment)

\section{Indirect Costs}

A. Engineering and supervision (5-30\% of direct cost)

B. Legal expenses (1-3\% of fixed capital investment)

C. Construction expense and contractor's fee (10-20\% of fixed capital investment)

D. Contingency (5-15\% of fixed capital investment)

III. Fixed Capital Investment ( = Direct Costs + Indirect Costs )

IV. Working Capital ( 10-20\% of Total Capital Investment )

V. Total Capital Investment ( = Fixed Capital Investment + Total Capital Investment )

${ }_{\text {F}}^{\ddagger}$ Please notice that all of costs are updated to 2014 by Chemical Engineering Plant Cost Indexes.

Table 3 Pd-based CMR specifications used for cost analysis

\begin{tabular}{|c|c|}
\hline Pd thickness $[\mu \mathrm{m}]$ & 8.300 \\
\hline Outer diameter of the support tube [m] & 0.025 \\
\hline Length of the support tube $[\mathrm{m}]$ & 0.356 \\
\hline Length of the porous part [m] & 0.254 \\
\hline Outer diameter of the shell casing $[\mathrm{m}]$ & 0.051 \\
\hline Wall thickness of shell casing [m] & 0.00305 \\
\hline Inner diameter of the shell casing $[\mathrm{m}]$ & 0.045 \\
\hline Length of the shell casing $[\mathrm{m}]$ & 0.914 \\
\hline Membrane area $\left[\mathrm{m}^{2}\right]$ & 0.0203 \\
\hline Volume for shell casing $\left[\mathrm{m}^{3}\right]$ & 0.00143 \\
\hline Annular volume for catalyst packing $\left[\mathrm{m}^{3}\right]$ & 0.00027 \\
\hline Void fraction of catalyst (assumed) & 0.657 \\
\hline Catalyst dilution (assumed) & 0.800 \\
\hline Solid catalyst density (calculation) $\left[\mathrm{kg} / \mathrm{m}^{3}\right]$ & 2130.000 \\
\hline Catalyst bed density (calculation) $\left[\mathrm{kg} / \mathrm{m}^{3}\right]$ & 1119.528 \\
\hline Weight of catalyst $[\mathrm{kg}]$ & 0.302 \\
\hline
\end{tabular}


Table 4 Probability distributions associated with various uncertainty drivers

\begin{tabular}{|c|c|c|}
\hline Uncertainty driver & Minimum & Maximum \\
\hline $\mathrm{Pd}$ unit price $[\$ / \mathrm{g}], \mathrm{RH}$ & \multicolumn{2}{|c|}{ Historical data from 2011-2015, www.kitco.com } \\
\hline Electroless plating setup cost [\$], UD & 1000 & 2000 \\
\hline Ratio for Operating labor, UD ${ }^{\mathrm{a}}$ & $12.5 \%$ & $50.0 \%$ \\
\hline $\begin{array}{l}\text { Ratio for Direct supervisory and clerical labor, } \\
\text { UD }^{\mathrm{b}}\end{array}$ & $10.0 \%$ & $20.0 \%$ \\
\hline Ratio for Utilities, $U^{\mathrm{a}}$ & $12.5 \%$ & $50.0 \%$ \\
\hline Ratio for Maintenance and repair, $U^{c}$ & $2.0 \%$ & $10.0 \%$ \\
\hline Ratio for Operating supplies, $U^{c}{ }^{c}$ & $0.5 \%$ & $1.0 \%$ \\
\hline Ratio for Laboratory charges, $U^{b}$ & $10.0 \%$ & $20.0 \%$ \\
\hline Ratio for Patents and royalties, UD ${ }^{\mathrm{a}}$ & 0 & $15.0 \%$ \\
\hline Ratio for installation, $U^{d}$ & $25.0 \%$ & $55.0 \%$ \\
\hline $\begin{array}{l}\text { Ratio for instrumentation and controls, installed, } \\
U^{d}\end{array}$ & $8.0 \%$ & $50.0 \%$ \\
\hline Ratio for piping, installed, $U^{d}$ & $10.0 \%$ & $80.0 \%$ \\
\hline Ratio for electrical, installed, $U^{d}$ & $10.0 \%$ & $40.0 \%$ \\
\hline Ratio for buildings, process and auxiliary, $U^{d}$ & $10.0 \%$ & $70.0 \%$ \\
\hline $\begin{array}{l}\text { Ratio for service facilities and yard } \\
\text { improvements, UD }\end{array}$ & $40.0 \%$ & $100.0 \%$ \\
\hline Ratio for land, UD ${ }^{\mathrm{d}}$ & $4.0 \%$ & $8.0 \%$ \\
\hline Ratio for engineering and supervision, $\mathrm{UD}^{\mathrm{e}}$ & $5.0 \%$ & $30.0 \%$ \\
\hline Ratio for legal expenses, $U^{\mathrm{f}}$ & $1.0 \%$ & $3.0 \%$ \\
\hline $\begin{array}{l}\text { Ratio for construction expense and contractor's } \\
\text { fee, } U^{f}\end{array}$ & $10.0 \%$ & $20.0 \%$ \\
\hline Ratio for contingency, $U^{f}$ & $5.0 \%$ & $15.0 \%$ \\
\hline Ratio for working capital, UD ${ }^{\mathrm{g}}$ & $10.0 \%$ & $20.0 \%$ \\
\hline
\end{tabular}

$\mathrm{RH}=$ Resample historical data, $\mathrm{UD}=$ Uniform distribution

${ }^{a}$ Based on raw materials, ${ }^{b}$ Based on operating labor, ${ }^{c}$ Based on electroless plating setup cost,

${ }^{\mathrm{d}}$ Based on purchased equipment cost, ${ }^{\mathrm{e}}$ Based on direct cost,

${ }^{\mathrm{f}}$ Based on fixed capital investment, ${ }^{\mathrm{g}}$ Based on total capital investment. 
Table 5 WGS-CMR module cost summary

\begin{tabular}{|c|c|c|c|c|}
\hline & \multicolumn{2}{|c|}{ Fixed capital investment } & \multicolumn{2}{|c|}{ Total capital investment } \\
\hline & {$[\mathrm{k} \$]$} & {$\left[\mathrm{k} \$ / \mathrm{m}^{2}\right]$} & {$[\mathrm{k} \$]$} & {$\left[\mathrm{k} \$ / \mathrm{m}^{2}\right]$} \\
\hline $\mathrm{P}_{95}$ & 472.4 & 23,319 & 560.4 & 27,664 \\
\hline Expected value & 385.5 & 19,028 & 454.1 & 22,418 \\
\hline $\mathrm{P}_{5}$ & 305.3 & 15,070 & 357.5 & 17,649 \\
\hline
\end{tabular}




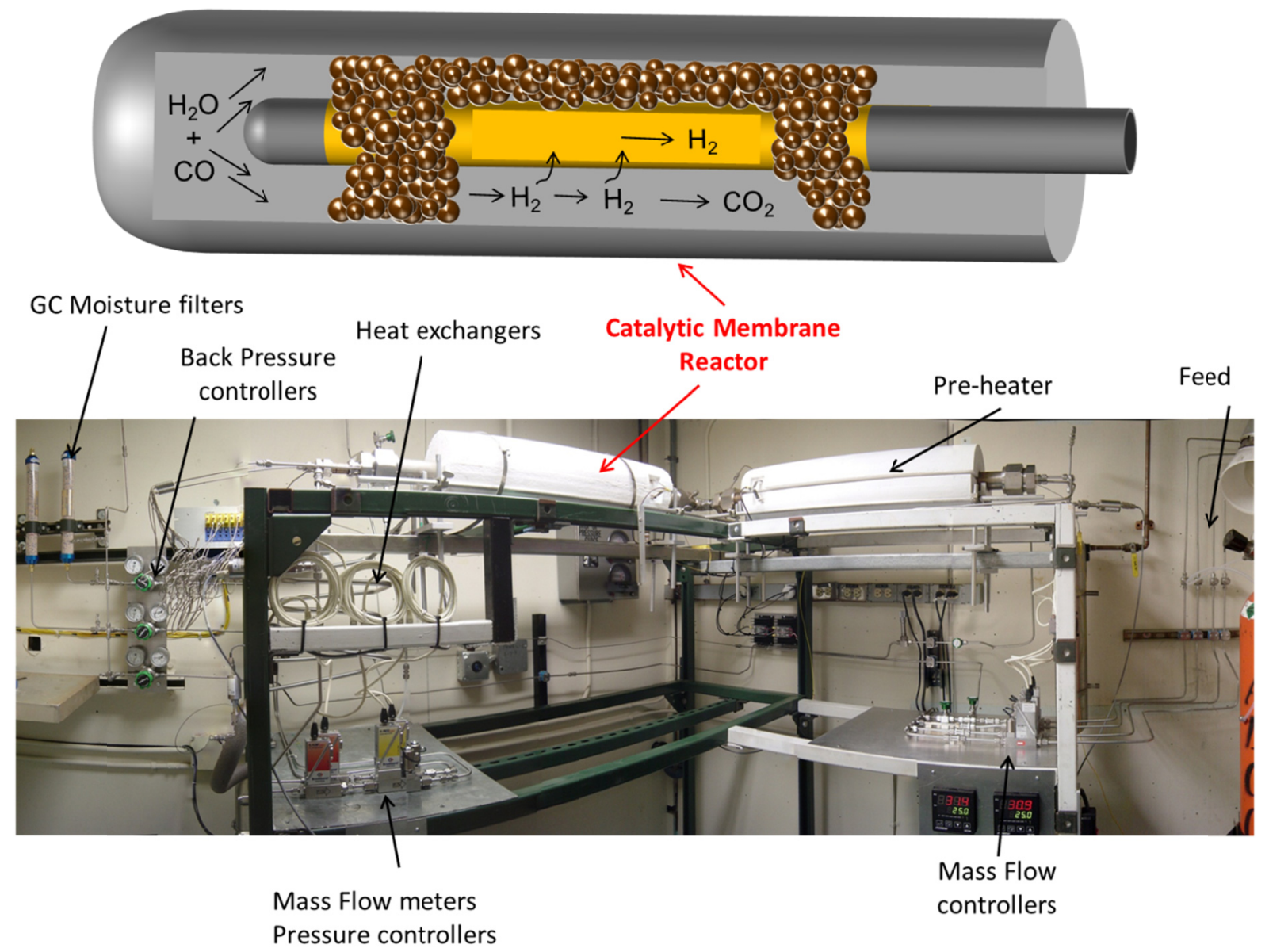

Figure 1. Schematic of a CMR module for water gas shift reaction and picture of the actual CMR rig built at WPI 


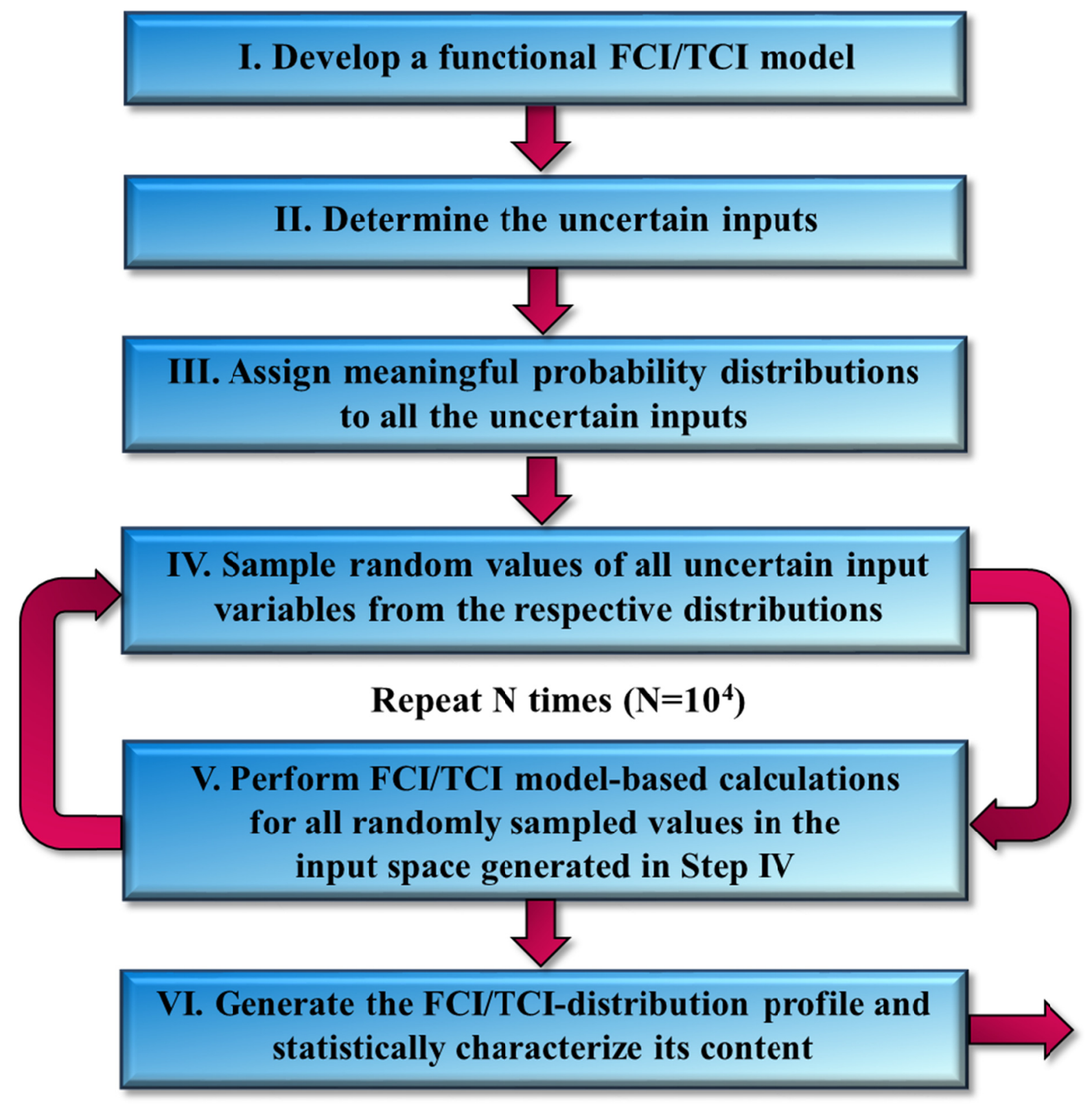

Figure 2. Procedural steps of the Monte Carlo simulation method [14] 


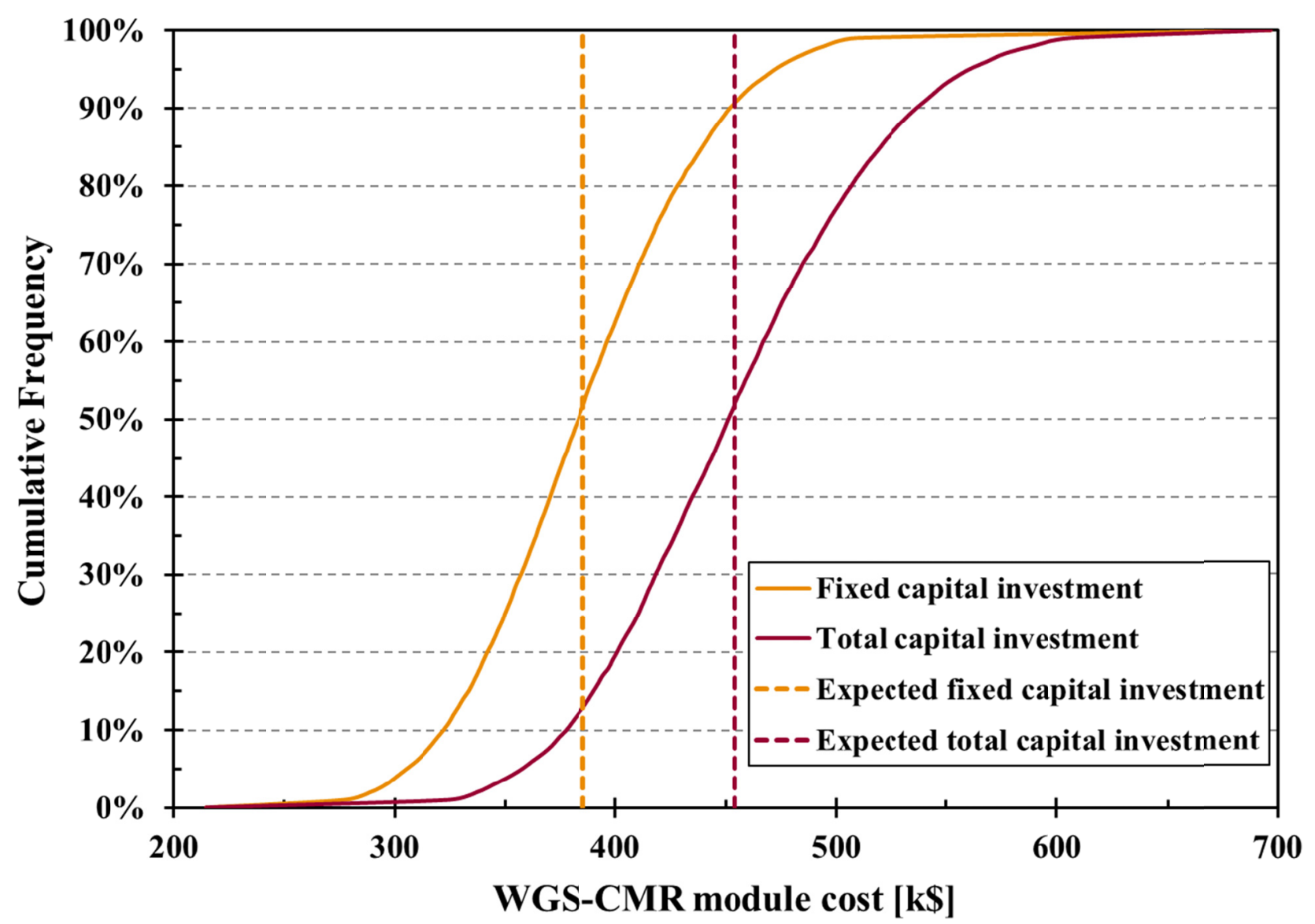

Figure 3. Cost distribution profiles of the WGS-CMR module 


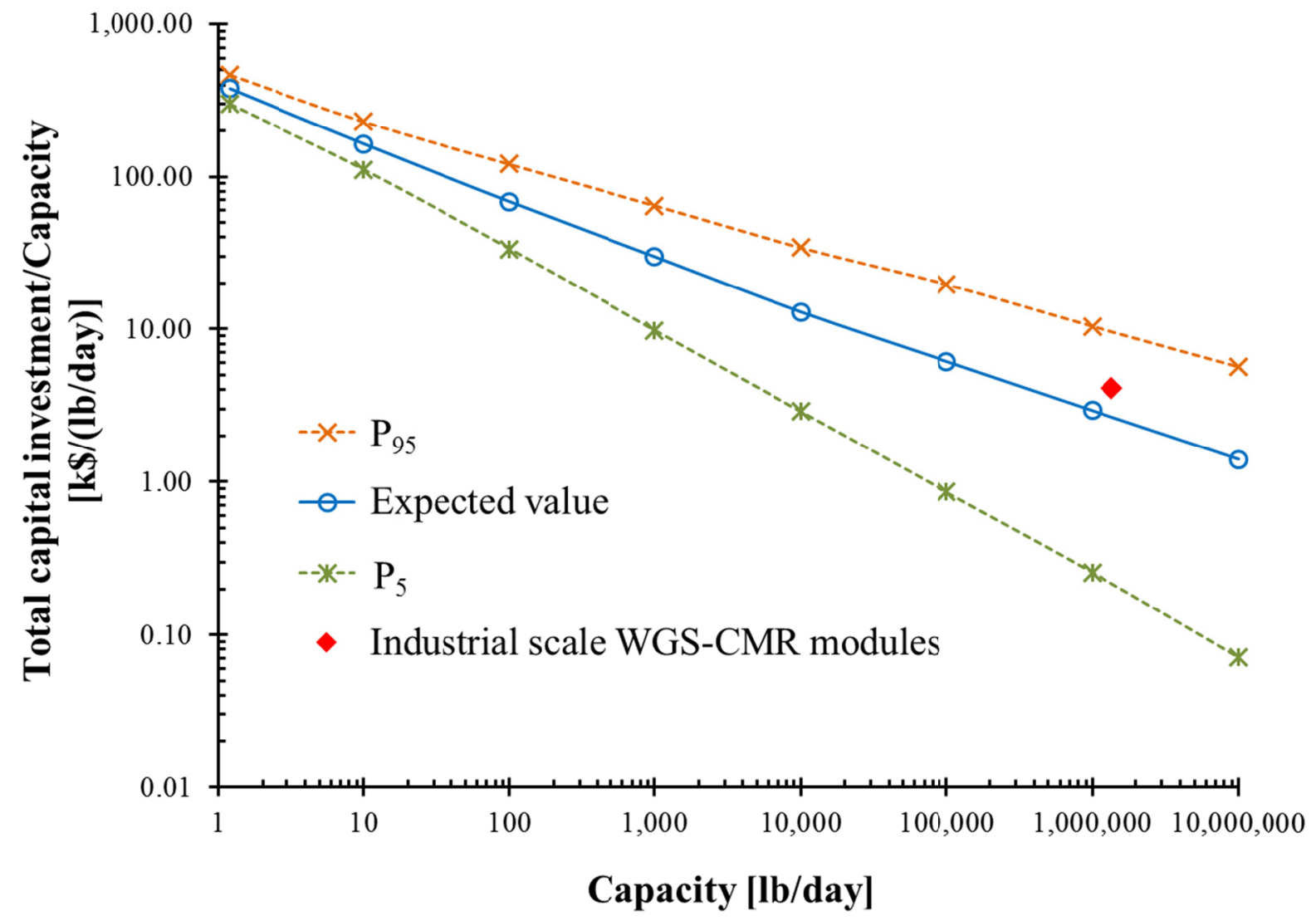

Figure 4: Normalized Total Capital Investment of WGS-CMR modules for various capacities. 


\begin{tabular}{|c|c|c|c|c|c|c|c|}
\hline \multicolumn{8}{|c|}{ ETCI $[\mathrm{k} \mathbf{S}]$} \\
\hline & 400 & 420 & 440 & 460 & 480 & 500 & 52 \\
\hline \multirow{2}{*}{\multicolumn{8}{|c|}{$\begin{array}{r}\text { Capacity of purchased equipment } \\
\text { Engineering and supervision }\end{array}$}} \\
\hline & & & & & & & \\
\hline \multicolumn{8}{|l|}{ Piping, installed } \\
\hline \multirow{2}{*}{\multicolumn{8}{|c|}{$\begin{array}{l}\text { Buildings, process and auxiliary } \\
\text { Service facilities and yard improvements }\end{array}$}} \\
\hline & & & & & & & \\
\hline \multicolumn{8}{|l|}{ Contingency } \\
\hline \multicolumn{8}{|l|}{ Construction expense and contractor's fee } \\
\hline \multicolumn{8}{|l|}{ Instrumentation and controls } \\
\hline Working capital & & & & & & & घHigh \\
\hline Electrical, installed & & & $=$ & & & & \\
\hline Installation & & & & & & & WLow \\
\hline Legal expenses & & & & & & & \\
\hline Land & & & & & & & \\
\hline Operating labor & & & & & & & \\
\hline Utilities & & & & & & & \\
\hline Patents and royalties & & & & & & & \\
\hline Maintanence and repair & & & 1 & & & & \\
\hline Electroless plating setup cost & & & & & & & \\
\hline Pd unit price & & & i & & & & \\
\hline Direct supervisory and clerical labor & & & & & & & \\
\hline Laboratory charges & & & & & & & \\
\hline Operating supplies & & & 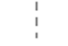 & & i & & \\
\hline
\end{tabular}

Figure 5. Tornado diagram for Total Capital Investment 


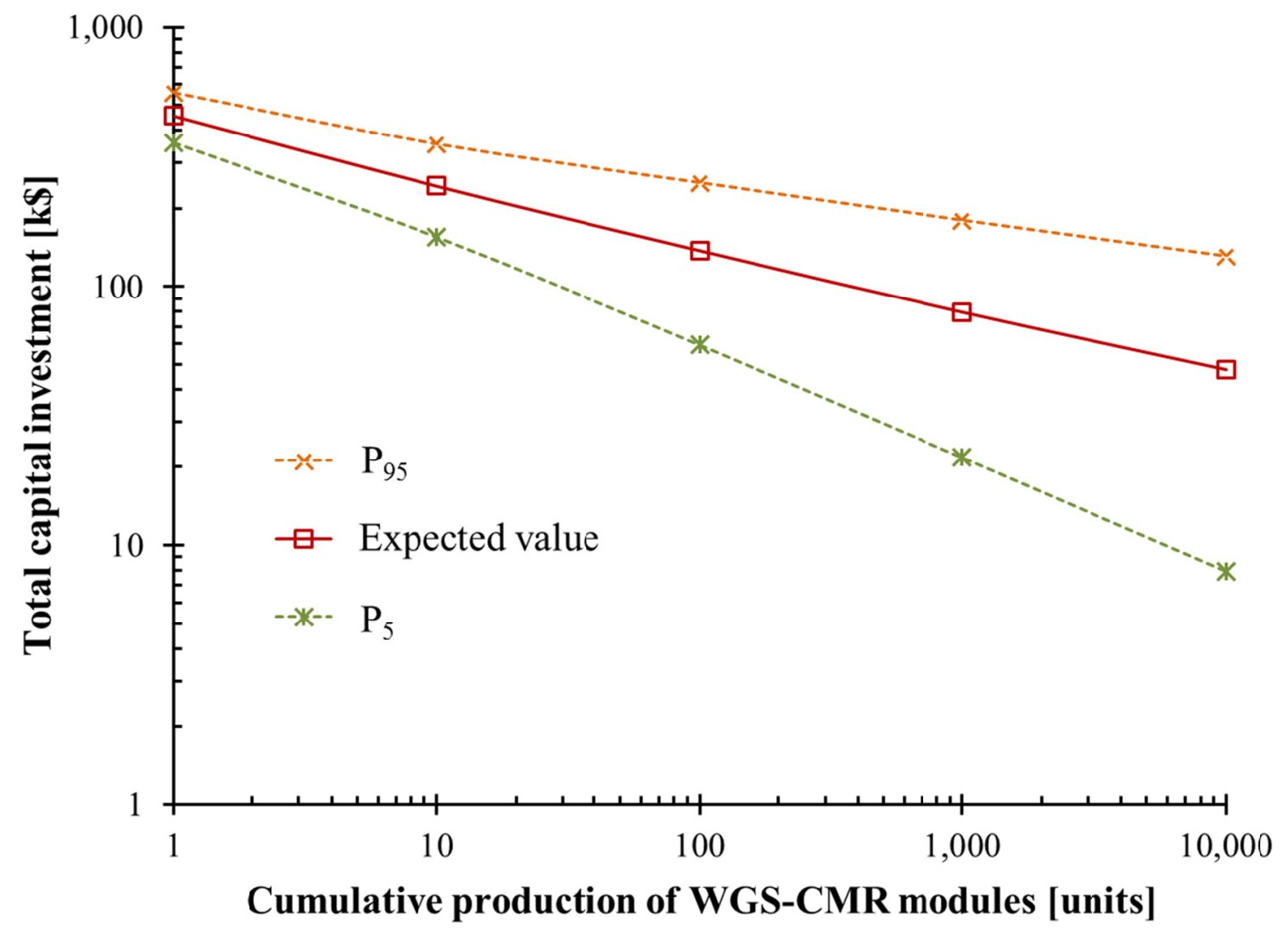

Figure 6: Experience curve for Total Capital Investment of WGS-CMR modules. 
Appendix. Historical palladium unit price from 2011 to 2015 (Data adapted from www.kitco.com)

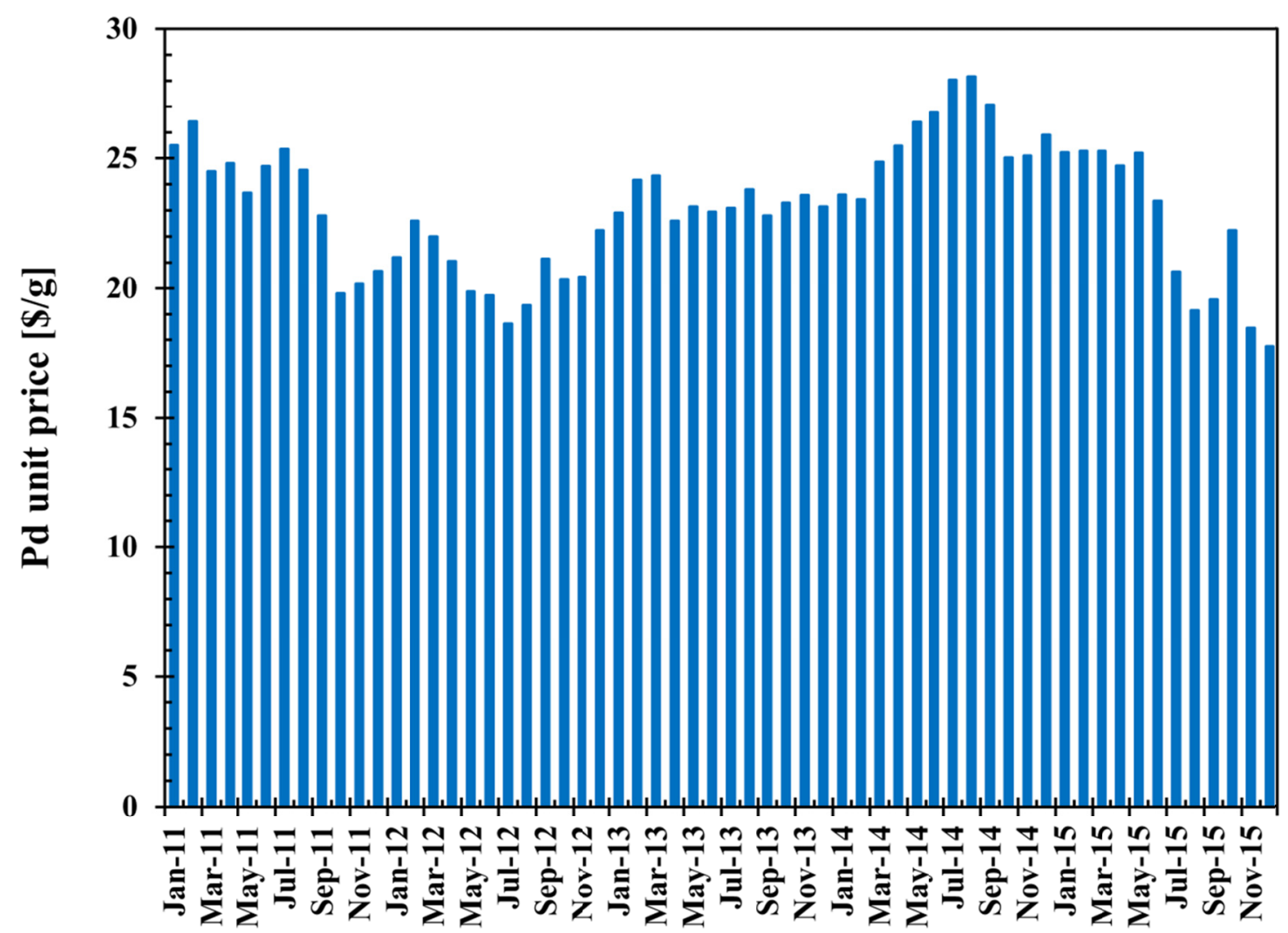




\section{References}

[1] Catalano J, Guazzone F, Mardilovich IP, Kazantzis NK and Ma YH (2013) Hydrogen Production in a Large Scale Water Gas Shift Pd-Based Catalytic Membrane Reactor. Industrial and Engineering Chemistry Research 52(3): 1042-1055.

[2] Paglieri SN, Way JD, (2002) Innovations in Palladium Membrane Research. Separation and Purification Methods 31 (1): 1-169.

[3] Huang TC, Wei MC, Chen HI, (2003) Preparation of hydrogen-permselective palladiumsilver alloy composite membranes by electroless co-deposition. Separation and Purification Technology 32 (1-3): 239-245.

[4] Hatlevik Ø, Gade SK, Keeling MK, Thoen PM, Davidson AP, Way JD, (2010) Palladium and palladium alloy membranes for hydrogen separation and production: History, fabrication strategies, and current performance. Separation and Purification Technology 73 (1): 59-64.

[5] Brunetti A, Caravella A, Fernandez E, Pacheco Tanaka DA, Gallucci F, Drioli E, Curcio E, Viviente JL and Barbieri G (2015) Syngas upgrading in a membrane reactor with thin Pd-alloy supported membrane. International Journal of Hydrogen Energy 40(34): 10883-10893.

[6] Basile A, Curcio S, Bagnato G, Liguori S, Jokar SM and Iulianelli A (2015) Water gas shift reaction in membrane reactors: Theoretical investigation by artificial neural networks model and experimental validation. International Journal of Hydrogen Energy 40(17): 5897-5906.

[7] Lin YM, Rei MH (2001) Separation of hydrogen from the gas mixture out of catalytic reformer by using supported palladium membrane. Separation and Purification Technology 25 (1-3): 87-95.

[8] Adams BD and Chen A (2011) The role of palladium in a hydrogen economy. Materials Today 14(6): 282-289.

[9] Chou VH and Kuehn NJ (2010) Assessment of Hydrogen Production with $\mathrm{CO}_{2}$ Capture. Vol. 1: Baseline State-of-the-Art Plants. National Energy Technology laboratory, US Department of Energy, Pittsburgh, PA, USA. See http://www.netl.doe.gov/File\%20Library/Research/Energy\%20Analysis/Coal/H2 Prod Vol1 2010.pdf (accessed 20/09/14).

[10] Iaquaniello G, Giacobbe F, Morico B, Cosenza S and Farace A (2008) Membrane reforming in converting natural gas to hydrogen: Production costs, Part II. International Journal of Hydrogen Energy 33(22): 6595-6601. 
[11] De Falco M, Salladini A, Palo E and Iaquaniello G (2015) Pd-Alloy Membrane Reactor for Natural Gas Steam Reforming: an Innovative Process Design for the Capture of $\mathrm{CO}_{2}$, Industrial and Engineering Chemistry Research 54(27): 6950-6958.

[12] Balat M (2008) Possible Methods for Hydrogen Production. Energy Sources, Part A: Recovery, Utilization, and Environmental Effects 31(1): 39-50.

[13] Ayturk ME, Kazantzis NK and Ma YH (2009) Modeling and performance assessment of Pd- and Pd/Au-based catalytic membrane reactors for hydrogen production. Energy and Environmental Science 2: 430-438.

[14] Ma LC, Castro-Dominguez B, Kazantzis NK and Ma YH (2015) Integration of membrane technology into hydrogen production plants with $\mathrm{CO}_{2}$ capture: An economic performance assessment study. International Journal of Greenhouse Gas Control 42: 424-438.

[15] Said SAM, Simakov DSA, Mokheimer EMA, Habib MA, Ahmed S, Waseeuddin M and Román-Leshkov Y (2015) Computational fluid dynamics study of hydrogen generation by low temperature methane reforming in a membrane reactor. International Journal of Hydrogen Energy 40(8): 3158-3169.

[16] Cornaglia L, Múnera J and Lombardo E (2015) Recent advances in catalysts, palladium alloys and high temperature WGS membrane reactors: A review. International Journal of Hydrogen Energy 40(8): 3423-3437.

[17] Patrascu M and Sheintuch M (2015) On-site pure hydrogen production by methane steam reforming in high flux membrane reactor: Experimental validation, model predictions and membrane inhibition. Chemical Engineering Journal 262(15): 862-874.

[18] Mardilovich IP, Castro-Dominguez B, Kazantzis NK, Wu T and Ma YH (2015) A comprehensive performance assessment study of pilot-scale $\mathrm{Pd}$ and $\mathrm{Pd} /$ alloy membranes under extended coal-derived syngas atmosphere testing. International Journal of Hydrogen Energy 40(18): 6107-6117.

[19] Guazzone F, Catalano J, Mardilovich IP, Kniep J, Pande S, Wu T, Lambrecht RC, Datta S, Kazantzis NK and Ma YH (2012) Gas permeation field tests of composite Pd and Pd-Au membranes in actual coal derived syngas atmosphere. International Journal of Hydrogen Energy 37(19): 14557-14568.

[20] Koc R, Kazantzis NK and Ma YH (2014) Membrane technology embedded into IGCC plants with $\mathrm{CO}_{2}$ capture: An economic performance evaluation under uncertainty. International Journal of Greenhouse Gas Control 26: 22-38. 
[21] Ma LC, Kazantzis NK and Ma YH (2015) Natural gas in hydrogen production: a cost study. Proceedings of the Institution of Civil Engineers - Energy 168(1): 61-73.

[22] Koc R, Kazantzis NK and Ma YH (2011) A process dynamic modeling and control framework for performance assessment of $\mathrm{Pd} /$ alloy-based membrane reactors used in hydrogen production. International Journal of Hydrogen Energy 36(8): 4934-4951.

[23] Koc R, Kazantzis NK, Nuttall WJ and Ma YH (2012) Economic assessment of inherently safe membrane reactor technology options integrated into IGCC power plants. Process Safety and Environmental Protection 90: 436-450.

[24] Koc R, Kazantzis NK, Nuttall WJ and Ma YH (2013) An economic evaluation framework for membrane reactor modules in the presence of uncertainty: The case for process safety investment and risk reduction. Journal of Loss Prevention in the Process Industries 26: 468-477.

[25] Savage SL (2003) Decision Making with Insight. Brooks/Cole, Belmont, CA, USA.

[26] Peters M, Timmerhaus K and West R (2003) Plant Design and Economics for Chemical Engineers. McGraw-Hill Education, New York, NY, USA.

[27] Chemical Engineering (2014) Plant Cost Indexes. Chemical Engineering. Access Intelligence Publishing, New York, NY, USA. See http:// www.chemengonline.com/pci (accessed 20/06/15).

[28] Glasserman P (2003) Monte Carlo Methods in Financial Engineering. Springer Science + Business Media, New York, NY, USA.

[29] Simon JL (1997) Resampling: The new statistics. Resampling Stats, Arlington, VA, USA.

[30] Barmish BR and Lagoa CM (1997) The uniform distribution: A rigorous justification for its use in robustness analysis, Mathematics of Control, Signals, and Systems 10: 203-222.

[31] Kuipers L and Niederreiter H (2002) Uniform Distribution of Sequences. Dover Publications, Mineola, NY, USA.

[32] Seider WD, Seader JD and Lewin DR (2004) Product and Process Design Principles, Synthesis, Analysis and Evaluation, Second Edition. John Wiley and Sons, Hoboken, NJ, USA.

[33] de Neufville R and Scholtes S (2011) Flexibility in Engineering Design. MIT Press, Cambridge, MA, USA.

[34] Haldi J, Whitcomb D (1967) Economies of Scale in Industrial Plants. Journal of Political Economy 75 (4):373-385. 
[35] Lieberman MB (1987) Market Growth, Economies of Scale and Plant Size in the Chemical Processing Industries. Journal of Industrial Economics 36 (2): 175-191.

[36] Sjardin M, Damien KJ, Faaij APC (2015) Techno-economic prospects of small-scale membrane reactors in a future hydrogen-fuelled transportation sector. Energy 31 (14): 25232555 .

[37] Christiansson L (1995) Diffusion and learning curves of renewable energy technologies. International Institute for Applied Systems Analysis, Laxenburg, Austria, Report no. WP-95126.

[38] Colpier UC and Cornland D (2002) The economics of the combined cycle gas turbine-an experience curve analysis. Energy Policy 30: 309-316. 